\title{
Disaster Tales as Communication Tool for Increasing Risk Resilience
}

\author{
Paola Mazzoglio ${ }^{1} \cdot$ Stefano Macchia $^{1} \cdot$ Enrico Gallo $^{2} \cdot$ Julia Winter $^{3} \cdot$ \\ Pierluigi Claps ${ }^{1}$
}

Accepted: 24 January 2021/Published online: 2 April 2021

(C) The Author(s) 2021

\begin{abstract}
Agencies in charge of flood management use disaster reports (DRs) as the preferred source of information on past flooding events. A systematic survey of DRs prepared by Italian agencies suggests that DRs could be widely enhanced in view of targeting more effective communication to citizens, reinforcing the communication pillar in civil protection planning and management, and improving the resilience of the population to extreme events. Without loss of the rigor and details required for all the usual technical uses of DRs, we suggest recompiling them in the form of "disaster tales" (DTs), as tools that offer wider knowledge of the events to improve people's preparedness and self-protection behavior. Recent major flooding events have demonstrated the communication potential that videos and pictures taken by citizens have for risk perception and disaster preparedness. By watching and listening to what has happened the communication recipient can better understand the feelings of the people experiencing an emergency. The structure of the improved reports, we suggest, will finally integrate data, graphs, and maps with interactive tools and be able to present handier multimedia views of the events. Application to three case studies of flooding in Italy illustrates how to concretely implement the suggested disaster reports to create more readily accessible disaster tales.
\end{abstract}

Paola Mazzoglio

paola.mazzoglio@polito.it

1 Department of Environment, Land and Infrastructure Engineering (DIATI - Dipartimento di Ingegneria dell'Ambiente, del Territorio e delle Infrastrutture), Politecnico di Torino, 10129 Torino, Italy

2 Comune di Torino, 10152 Torino, Italy

3 PwC (PricewaterhouseCoopers) Italy, 10122 Torino, Italy
Keywords Disaster communication · Disaster narratives $\cdot$ Flood risk perception $\cdot$ Italy $\cdot$ Storytelling

\section{Introduction}

Lack of basic technical knowledge can lead to a lower perception of flood risk (Botzen et al. 2009). People often underestimate a severe storm, or signs of an impending one, and continue to pursue normal activities that could turn out to be potentially fatal. The misperception of risk among Italians is a good example. The majority of the population considers earthquakes as the most likely risk, followed by floods, landslides, and volcanic activity, even though geohydrological events (landslides and floods) are far more frequent than geophysical events (earthquakes and volcanic activity) (Salvati et al. 2014).

In general, the social groups commonly considered vulnerable (for example, children and the disabled) show seemingly cautious behavior, while young people and adults often underestimate the risks in emergencies and carry on with their activities. As older people vary greatly in their health status and ability to adapt, the risks in emergencies to this portion of the population remain significant. Older people may also have stronger ties to their homes and communities than younger people and be less willing to evacuate or uproot (Hutton 2008).

Flash-flood events that have occurred in recent years have highlighted the high number of casualties recorded among drivers trapped in their vehicles or swept away by the raging flow. Drowning also takes place in people's basements or due to the violent impact of objects carried by fast-moving water (Jonkman and Kelman 2005; Ruin et al. 2008; Xia et al. 2011). At other times, when an imminent 
risk is perceived, people act in intuitive ways that are hardly ever influenced by reason. People often make heuristic decisions that are based on a few simple rules or on previous experiences rather than evaluating the entirety of the information available and quickly weighing between conflicting/competing options. This is an unconscious decision-making process governed by misperceptions through which information is selected and filtered before surfacing in the conscious sphere (Cagnati and Chiambretti 2009).

Salvati et al. (2014) revealed in two surveys (3122 telephone interviews in 2012 and 3126 telephone interviews in 2013 using two questionnaires) that the majority of the interviewees had no direct experience or indirect knowledge of landslides or flood events in their area. This was mainly due to lack of information and insufficient education on natural hazards and risks, and partly also to the low personal interest in this particular risk. Brilly and Polic (2005), among others, underlined the importance of educating and training people on natural hazards and on the right behavior during flood events. According to Lara et al. (2010), increased knowledge of the causes of events leads to higher citizen awareness of the risk. Every effort that encourages the dissemination of information about significant events, including their forecasting and their aftermath, is certainly useful.

The public perception of flood risk is often related to past experiences and, in particular, to the memory of floods that took place in the same areas. However, risk perception-and the related risk awareness-is at its highest immediately after a flood event and decreases rapidly after the event (Miceli et al. 2008). In the intuitive and preconscious decision-making process, the cultural context has particular importance, and also acts through the personal memory of the effects of past exceptional climatic events. It is important to highlight the results of recent reviews of flood risk communication as well. The need has emerged to create a theoretical framework, based on the social sciences, that addresses the systematic communication processes (Kellens et al. 2013).

It seems therefore important to select and synthesize the knowledge acquired from the scientific community and to apply it to public safety policies by identifying more effective communication strategies for passing on information on the dynamics of hazardous events and the causes of casualties. Traditional information channels include print sources such as newspapers, magazines, and brochures, or electronic sources such as radio and television; contemporary information channels include smartphone apps and the Internet; and sometimes in-person communications also apply (Lindell and Perry 2012; Tang et al. 2015).
In this article, we first describe and analyze the technical documents, that is, the disaster reports (DRs), that are drawn up by agencies operating in the Italian civil protection system after extreme weather events impacted the territory, causing economic and personal damages. Subsequently, we present tools to integrate these documents in order to improve risk knowledge and awareness. The main strategy adopted is the use of a narrative approach that turns DRs into disaster tales (DTs) with a precise storyline, which are more accessible and attractive for the general public. The storyline approach is used to represent the whole sequence of events during a flood. Instead of using "static" risk mapping, a storyline should consider the possible sequence of significant episodes during the event and the recovery phase (de Bruijn et al. 2016). A significant parallel example comes from Sanne (2008) who studied occupational health and safety incidents among railway maintenance technicians in Sweden and found that the incident-reporting scheme was not integrated into the technicians' cultural framework, while informal storytelling was closer to the technicians' practices to create risk awareness. In addition, a vast literature is available on the importance of near-miss-reporting for safety in the industry (Jones et al. 1999) and in the business sectors (Denning 2005).

To illustrate the expansion of technical documents into more accessible disaster tales and to provide different points of view, we use examples of the application of the storytelling approach to three flood events in Italy-two flash-flood events: (1) Salerno and Amalfi coast, 25-26 October 1954; and (2) Genoa, 4 November 2011; and one wide-area and short-duration flood event: (3) Sardegna, 18 November 2013. Salerno and the Amalfi coast are located in the Campania region, which has the highest landslide risk in Italy, while the city of Genoa in the Liguria region and the Sardegna region both have a high density of floods per $\mathrm{km}^{2}$ (Salvati et al. 2010).

\section{An Analysis of Disaster Reports in Italy}

In this section we analyze typical disaster reports, technical documents drawn up locally after extreme weather-related events (intense rainfall, floods, and landslides). They are produced mainly within the activity framework of the Decentralized Functional Centers of Civil Protection (DFCCP) (Table 1). These reports are written with the aim of gathering and summarizing information on the events and are mainly addressed to specialized technicians and experts.

We also considered some DRs drawn up by the National Department of Civil Protection for those regions that lacked a DFCCP at the time of the flood event. In Italy, 
Table 1 List of organizations in charge of civil protection and preparation of disaster reports in the 20 administrative regions of Italy

\begin{tabular}{|c|c|c|c|}
\hline $\begin{array}{l}\text { ISTAT } \\
\text { code }\end{array}$ & Region & $\begin{array}{l}\text { Organization } \\
\text { in charge }\end{array}$ & Website \\
\hline 01 & Piemonte & $\begin{array}{l}\text { ARPA } \\
\text { Piemonte }\end{array}$ & http://www.arpa.piemonte.it/pubblicazioni-2/relazioni-tecniche/analisi-eventi \\
\hline 02 & Valle d'Aosta & DFCCP & https://cf.regione.vda.it/rapporti_di_evento.php \\
\hline 03 & Lombardia & $\begin{array}{l}\text { ARPA } \\
\text { Lombardia }\end{array}$ & $\begin{array}{l}\text { https://www.arpalombardia.it/Pages/Acque-Superficiali/Quantita/Bollettini-e- } \\
\text { rapporti.aspx }\end{array}$ \\
\hline $04(021)^{\mathrm{a}}$ & $\begin{array}{l}\text { Autonomous Province of } \\
\text { Bolzano-Alto Adige }\end{array}$ & DFCCP & http://www.provincia.bz.it/sicurezza-protezione-civile/ \\
\hline $04(022)$ & $\begin{array}{l}\text { Autonomous Province of } \\
\text { Trento }\end{array}$ & DFCCP & https://www.meteotrentino.it/\#!/content?menuItemDesktop=45 \\
\hline 05 & Veneto & DFCCP & https://www.regione.veneto.it/web/protezione-civile/relazioni-eventi \\
\hline 06 & Friuli Venezia Giulia & DFCCP & https://www.protezionecivile.fvg.it/it/centro-funzionale-decentrato \\
\hline 07 & Liguria & ARPA Liguria & $\begin{array}{l}\text { https://www.arpal.liguria.it/homepage/meteo/pubblicazioni/rapporti-di-eventi- } \\
\text { significativi.html }\end{array}$ \\
\hline 08 & Emilia-Romagna & $\begin{array}{l}\text { ARPA Emilia- } \\
\text { Romagna }\end{array}$ & https://allertameteo.regione.emilia-romagna.it/archivio-report-post-evento \\
\hline 09 & Toscana & DFCCP & https://www.cfr.toscana.it/index.php?IDS=23\&IDSS=191 \\
\hline 10 & Umbria & DFCCP & http://www.cfumbria.it/index.php?s=10126 \\
\hline 11 & Marche & DFCCP & $\begin{array}{l}\text { https://www.regione.marche.it/Regione-Utile/Protezione-Civile/Progetti-e- } \\
\text { Pubblicazioni/Rapporti-di-evento }\end{array}$ \\
\hline 12 & Lazio & DFCCP & $\begin{array}{l}\text { http://www.idrografico.regione.lazio.it/new/idrografico/start.php-page=Rapporti\% } \\
\text { 20evento.htm }\end{array}$ \\
\hline 13 & Abruzzo & DFCCP & https://protezionecivile.regione.abruzzo.it/index.php/centro-funzionale-d-abruzzo \\
\hline 14 & Molise & DFCCP & http://www.protezionecivile.molise.it/documentazione/studi-e-pubblicazioni.html \\
\hline 15 & Campania & DFCCP & http://centrofunzionale.regione.campania.it/\#/pages/documenti/rapporti \\
\hline 16 & Puglia & DFCCP & https://protezionecivile.puglia.it/centro-funzionale-decentrato/report-di-evento/ \\
\hline 17 & Basilicata & DFCCP & http://centrofunzionalebasilicata.it/it/report-idrologici.php \\
\hline 18 & Calabria & DFCCP & http://www.cfd.calabria.it/index.php/pubblicazioni/voce-2 \\
\hline 19 & Sicilia & DFCCP & $\begin{array}{l}\text { https://www.protezionecivilesicilia.it/it/199-documentazione-del-cfdmi.asp and } \\
\text { http://www.osservatorioacque.it/?cmd=page\&id=centrocomp_rapportie } \\
\text { vento\&tpl=default }\end{array}$ \\
\hline 20 & Sardegna & DFCCP & http://www.sardegnaambiente.it/protezionecivile/ \\
\hline
\end{tabular}

ISTAT istituto nazionale di statistica/national statistical institute, ARPA agenzia regionale per la protezione ambientale/regional environmental protection agency, $D F C C P$ centro funzionale decentrato della protezione civile/decentralized functional centers of civil protection.

${ }^{a}$ The provinces of Trento and Bolzano are reported separately in this table because civil protection activities are handled by different organizations, even if they are located in the same administrative region. The ISTAT code reported in parentheses is the ISTAT code of the province ( 021 for the Autonomous Province of Bolzano - Alto Adige and 022 for the Autonomous Province of Trento) while 04 is the ISTAT code of the region.

only in recent years (starting from the end of the 1990s) the civil protection activities are decentralized, that is, managed at the regional and lower levels. Before the creation of the DFCCPs (for example, for the Salerno case study), these occasional reports were included in the Hydrological Yearbooks ${ }^{1}$ published by the National Hydrological and Mareographic Service (SIMN - Servizio Idrografico e Mareografico Nazionale). The SIMN was decentralized during the 1990s and its duties, including the publication of DRs, were taken by the DFCCPs. The analysis of the

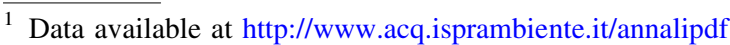

informative content of the DRs highlighted some common features found in almost all DRs, which are summarized below.

\subsection{Part 1-Description of the Event}

A section "Description of the Event" is always found in the reports and briefly accounts for the places, the times, and the duration of the event, its dynamics, as well as the most relevant phenomena. It is generally presented as a foreword. 


\subsection{Part 2-Meteorological Analysis}

The section "Meteo Analysis" is almost always included and the attention to detail varies depending on the issuing institution. The section's size increases according to the importance of the event under discussion. The comparison of the DRs of the first years of the 2000s and the ones written in recent years highlights a growing availability of sources for meteorological data and tools to present the meteorological framework in which the event evolved.

This part provides a description of the meteorological evolution of the event at a synoptic scale, normally by using charts of atmospheric pressure at ground level and geo-potential maps (rarely temperature and humidity). The most used weather forecast models (listed according to the frequency of use), whose output are reported in the DRs, are provided by:

- ECMWF (European Centre for Medium-Range Weather Forecasts);

- UKMO (United Kingdom Meteorological Office);

- NCEP (National Centers for Environmental Prediction);

- CNMCA (Centro Nazionale di Meteorologia e Climatologia Aeronautica).

In most cases the source is not explicitly reported. However, it can be deduced from indications alongside the maps.

In order to further document the evolution of meteorological events in DRs, images by EUMETSAT's Meteosat satellite (in visible or infrared bands) are often included. Alternatively, new yet increasingly common multispectral products represented with band composites, such as Airmass, can be found and the source can be deduced from the features of the images.

Some DRs present maps of the mosaic weather radar reflectivity and of radar estimated rainfall (instantaneous and cumulative) to provide a representation of the areal rain conditions (in other cases, the same map is shown in the "Rainfall Analysis" section). Sometimes it is possible to find a lightning map. Very rarely data from radio sounding can be found (for example, temperature profiles).

\subsection{Part 3-Rainfall Analysis}

The section regarding the analysis of rainfall data is always included in DRs, and it is usually the one that presents the largest amount of collected data. Hourly and cumulative rainfall data are typically published in the form of tables. Often it is possible to find comparisons of precipitation values with an intensity-duration-frequency curve that can highlight the importance (rarity) of the event.
In addition to punctual data, maps of the areal rainfall with isohyets are often available. These are obtained by interpolating the rainfall data (through inverse distance weighting or geostatistical analyses). Information about rainfall, its intensity, and isohyet maps are also always present in the DRs found in the Hydrological Yearbooks.

Some DRs present data from the DEWETRA processing and visualization platform, which operates at the National Department of Civil Protection. DEWETRA provides, through a graphical interface, high resolution and continuously updated information, allowing the user to monitor weather events, build detailed risk scenarios, and evaluate the potential impact of phenomena on communities and infrastructures. Finally, information on rainfall in the days preceding the event and soil moisture estimation (HSAFH14 model) may also be found in this section, if some additional analyses have taken place.

\subsection{Part 4-Hydrometric Analysis}

The hydrometric analysis is found frequently in DRs. It is omitted in the case that the event did not lead to measurable flooding, for example, in an urban environment. Data collected are typically shown as flood hydrographs recorded at the official gauging stations, with water levels or flow rates often compared to threshold levels. Occasionally one can find the delimitation of the catchment area affected by the event, in which case the exact position of the basin outlet is shown on the map.

In rare cases, a further description is also included regarding the hydraulic operations on dam and reservoir gates (with data of discharge in time) that may have changed the evolution of the event. Information about water levels and peak discharges is also present in the DRs found in the Hydrological Yearbooks.

\subsection{Part 5-Supplementary Analyses}

In order to properly describe the event, DRs occasionally present supplementary analyses, such as a thermometric analysis, zero-degree isotherm maps, a nivometric analysis (with occasional estimates of the snow water equivalent), an anemometric analysis, and the height of sea waves.

\subsection{Part 6-Ground Effects and Photo Report}

The section on the ground effects of the event is not always available as part of DRs, even if it has a strong communicative impact on people. When available, it typically contains photos of the damage caused by the event. These can directly belong to the agency releasing the DR or are obtained from the press or other amateur witnesses. In this section, like in the previous ones, the indication of the 
location of the damage is provided by using the name of the place rather than using a geographic map. Pictures of the event are also sometimes present in the DRs found in the Hydrological Yearbooks.

\subsection{Part 7-Reports and Notices Issued}

The DR can end (or, more rarely, start) with the alert notices issued before and during the event. This kind of information has become more and more important in Italy after approval of the Civil Protection Directive 10/26/2016 about the standards to use all over Italy for event alerts.

\section{Information and Communication Strategies}

The availability at the Italian national scale of DRs with a substantial homogeneity in terms of minimum contents, similar to the event analyses already published in the Hydrological Yearbooks, suggests a possible appreciation by expert and non-expert users of the information collected in a process of communication aimed at the increase of awareness and resilience.

People are getting more and more familiar with bulletins (daily reports) and warning messages that are very concise and, since 2016, fully uniform in content all over Italy. But the DRs are less known and are drawn up when the event is over. They allow for a more accurate analysis of hydrological data, a post-event critical review of the forecasts, and an overall charting of the effects of the event in terms of casualties and damage. Therefore, the DR is a priority document with important technical information but so far it is mainly addressed at a limited number of specialized technicians and almost never considered with respect to its inherent education potential. A report aimed at promoting greater resilience should:

- Communicate and explain the causes and the evolution of the event;

- Review and keep a log of past flood events (starting from the 1930s, when the practice of drawing up disaster reports started), and highlight the limits in the management of an emergency;

- Communicate and reiterate what behavior people should avoid during an event.

With respect to the identification of an appropriate communication strategy, the national and international literature recognizes the narrative approach as a powerful instrument to ensure that an event, not only in its traumatic aspects, remains in the social and collective memory of the population.

Storytelling is the basic mode of human interaction and a fundamental way of acquiring knowledge (Hinyard and
Kreuter 2007). The purpose of storytelling is not only to describe a situation but also to motivate people to act in a certain way (Kreuter et al. 2007). Narrative theory is based on the assumption that humans are natural storytellers who understand and interpret their life experiences as ongoing narratives (Fisher 1984). Various branches of narrative theory explore the essential nature of stories and explain how stories/narrative messages help people make sense of their world and the process through which a listener/viewer constructs meaning from a narrative and what attributes make a narrative/story interesting, transporting, and persuasive (Murphy et al. 2013; Lee et al. 2016). One essential help comes from the inclusion of details that are familiar to the listener/reader, with which the narrator can help the listeners/readers imagine themselves into the story. If the situation has the potential to involve the reader, it becomes "personally" relevant- the more personally relevant the story is, the more it will be remembered (Denning 2005).

An example of how a storyline approach can be used in flood risk management is given by de Bruijn et al. (2016), who proposed a stepwise analysis with a real application in Dordrecht, the Netherlands, during three critical phases: (1) the rising of the flood threat; (2) the flooding itself; and (3) the recovery from the flooding. After describing the system as a whole according to its physical and societal characteristics, and selecting a scenario, storylines are developed by the authors based on literature, flood simulations, and interviews with emergency managers, local authorities, and critical infrastructure operators.

When envisioning a reorganization of the material given in DRs through the selection and integration of further information, the creation of a "disaster tale" rather than a "disaster report" requires some distinct efforts:

1. Development of a Clear Temporal Sequence and Spatial Evolution of the Event

According to the narrative approach, a key element of tales is the organization of the information in a chronologic sequence. A typical sequence in DRs is:

- Analysis of data, models, and forecast bulletins;

- Critical alerts and warnings. Communication of selfprotection behavior;

- Evolution of the event with respect to rainfall and discharge;

- Ground effects, damage, and casualties;

- Summary and concluding comments.

A summary of the spatial and temporal evolution of the event is briefly outlined in "Description of the Event" in DRs. This, however, is not enough to appreciate the temporal sequence and the spatial evolution of the event or, for example, to realize how much time goes by between the time the bulletins and warnings are issued and the time of the occurrence of the event. This 
limit could partly be overcome, in order to understand the timeline of the flood event, by using both maps with a temporal scale and sequences of maps with a synthetic and standard legend.

2. Focus on Personal Accounts of the Event

An additional characteristic of the storytelling approach is the integration of personal accounts and happenings within the narrative. Disaster reports are objective and impersonal, even in those sections that present images of the effects of flood events or press releases that usually use photographs taken after the events without specific reference to their location. The increasing availability of amateur videos on the web could lead to their integration in DRs and result in useful support of the narratives of events.

These particular resources are nowadays widespread, especially in the case of extreme flood events. They represent an important source of information, also due to geotagging procedures, time stamping, and video and per-frame metadata. Amateur videos, if analyzed, not only allow the gathering of quantitative and qualitative technical information about the flood event, but through watching and listening, also for the building of the "tales" of the event, including insights into people's emotions during the most significant moments of the flood event.

3. Simplified Presentation of Quantitative Data

A further aspect that needs in-depth analysis is the way quantitative and technical data are communicated and presented in DRs. Disaster reports supply a substantial quantity of technical information, which currently is usually expressed graphically. This approach, however, does not entirely satisfy the needs of the specialists-including the new types of journalists who work in crowd-sourcing journalism, collaborative journalism, and mash-up and datajournalism - or of the general public. The first would need full details in terms of Open Data, while the latter would like to understand the magnitude of the event by comparing it with other precedents, in order to realize how significant the flood event was as a whole. To tackle this issue regarding quantitative data, a series of options are suggested for each of the DR parts identified in Sect. 2:

- Part 2-Meteorological analysis The current contents are extremely specialized, whereas they could be limited to a time-lapse sequence of Meteosat and radar images with improved geographic landmarks, often missing in the original pictures;
- Part 3-Rainfall analysis It is often already rich in data. It would be appropriate to highlight some detailed information (for example, event size, intensity, duration, and freezing level) and relate it to the return period or to previous well-known events;

- Part 4-Hydrometric analysis The same options as for the rainfall analysis are valid. Data relating to reservoirs, if available, should be properly communicated, both in terms of the regulating effects and in comparison with the design discharges, to better explain how the possible mitigating role of the reservoirs was taken advantage of;

- Part 5-Supplementary analyses Part to be pointed out only if important for the better understanding of the event;

- Part 6-Ground effects and photo report This content is very relevant for the narrative of the event. It could be helpful to report absolute and relative timing regarding the rainfall accumulation and the hydrometric analyses. This often requires integration with videos made by amateurs or journalists;

- Part 7-Reports and notices issued This part becomes relevant only if the warnings can be correctly located in time within the evolution of the event and its effects on the territory.

4. Inclusion of Final Comments and Lessons Learned Given that human knowledge consists of explanations aimed at clarifying the causal relationships between a set of phenomena (Denning 2005), from the point of view of the disaster tale, it is also important to know how the event wraps up. To this end, the DR can end with a critical analysis, the lessons learned, or a testimony. These elements are important in order to build up a patrimony of knowledge to remind the citizens of the event.

The concluding summary should also highlight the importance of avoiding detrimental behaviors during a flood event, in order to reduce risks. It is advisable to support this part with photos, videos, or press reports. Disaster reports should also highlight the role of urbanization on the dynamics of the flood event.

To shift the narrative from the established disaster reports to more effective disaster tales, a change of perspective is needed. Table 2 summarizes the strategies illustrated in this section by comparing DRs and DTs. This shift would benefit from a social media communication strategy that targets risk awareness, which would help citizens implement self-protection strategies by using past flood events as reminders. 
Table 2 Comparison of communication strategies between disaster reports (DRs) and disaster tales (DTs)

\begin{tabular}{ll}
\hline Disaster reports & Disaster tales \\
\hline Aimed at specialized technicians & Targets all society \\
Technical and scientific approach & Narrative approach \\
Impersonal account of the event & Integration of personal accounts and experiences \\
Analytical report organized by themes & Structure focused on the temporal sequence and spatial evolution of the event \\
Quantitative data displayed as graphs & Simplified presentation of quantitative data, comparison with other events \\
Not enough importance is given to conclusions & Inclusion of final analysis and lessons learned \\
\hline
\end{tabular}

\section{Tools to Turn Disaster Reports into Disaster Tales}

The analysis conducted so far has highlighted the opportunity to restructure DRs as DTs with the aim of reaching a wider audience and improving risk knowledge and awareness in the general public. In line with the strategies suggested, this section illustrates, with some web- and mobile-oriented communication tools, how to manage and integrate DR content with other resources.

\subsection{Documents Dissemination and Web Upgrades}

A system for the systematic preparation of leaflets or brochures to report a disaster is not in place in Italy. This type of material is sometimes drawn up within projects focused on strengthening the memory of past events. According to the disaster tale paradigm, these informative documents may include a tale of the flood event, a geographical framework, and a timeline of the event that includes photos, graphics, or iconography. Additional resources, such as videos, blogs, web mapping, and so on may be included through links (also using Quick Response or $\mathrm{QR}$ codes). In the last decades, the diffusion of mobile phones and low-cost digital cameras has changed the public approach to catastrophes. When it comes to floods, images and videos taken in urban areas have become ubiquitous. Citizens often take the risk of recording during an event even in the most dangerous situations. These amateur videos are often used in news reports and can play a crucial role in the educational and technical representation of the issues and problems.

A leaflet cannot include videos, but can refer to them and can also contain self-protection advice with respect to the type of event. Similar advice is currently also disseminated through initiatives of good practice, such as "Io non rischio" (I do not risk) of the National Department of Civil Protection. $^{2}$

\footnotetext{
${ }^{2}$ http://iononrischio.protezionecivile.it.
}

\subsection{Web Mapping and Virtual Globe}

The online geographical software products that are accessible through either client application or browser constitute an essential instrument for integrating resources and data that have a temporal and geographic content. Among the several tools available, Google Earth represents the stateof-the-art. Through its KML standard format it enables the addition-onto a 3D flight simulation experience with bird's-eye view - of the visualization and query of cartographic levels typical of GIS environments (punctual, linear, and areal elements), as well as the use of other web resources linked to one of these elements. The potential of the Google Earth tool is very relevant for retracing flood events, essentially because:

- Various spatial and remote sensing data producers supply their data for consultation with protocols compatible with the environment of Google Earth;

- Google Earth allows the user to see photos and videos geo-referenced and synchronized with an event;

- It is possible to change the 3D model of the Earth's surface by choosing images from different moments in time or by adding an external one;

- It allows the user to integrate the visualization with 3D reconstructions, for example, created with SketchUp. Such 3D images are extremely helpful and effective when dealing with past events.

\subsection{Thematic Blog}

A thematic blog is often organized in short chronological contributions that are progressively updated and integrated with multimedia resources. This type of web resource is particularly effective in narrating the event and, at the same time, since it is frequently updated, it can give insight into the ongoing scrutiny and elaboration of every new piece of information that is collected throughout the event.

By showing documents of past events (official reports, photos, clips from newsreels and television archives, press articles, books, and publication extracts) and comparing 
them with the elements of the current event, a deeper understanding and grasping of the event is passed on to the reader. A relevant example of this type of initiative is Floodlist, ${ }^{3}$ a thematic blog that posts near real-time news about flood events from around the world with the aim of raising flood risk awareness.

\subsection{Crowdsourcing Platforms}

Crowdsourcing platforms store large amounts of data (for example, geo-referenced and time-tagged images and videos) that are often continuously received in real-time from a significant number of active users. The Ushahidi Platform ${ }^{4}$ is a good example of such a tool. It is particularly used in managing emergencies, especially in contexts with scarce infrastructures.

Crowdsourcing platforms are suitable-due to their browsing mode-for the collection of warnings, personal accounts, and documents for the reconstruction of events, both recent and past. Floodbook ${ }^{5}$ is an example of a platform that was developed to collect and share crowdsourced information collected from events that occurred across Italy. However, the success of a crowdsourcing platform largely depends on the members and their motivation to participate. This determines the quality and the quantity of the contributions (Janzik 2010). Finally, to manage and share vintage images and videos for events that happened in the pre-smartphone era, one can resort to specialized platforms, for example Hystorypin ${ }^{6}$ and WhatWasThere. ${ }^{7}$

\subsection{Street View Services}

Street view services are web applications that allow the user to see spherical images acquired at street level that give an immersive simulation of the environment. The best-known service is Google Street View, accessible through web mapping and virtual globe services; another interesting example is the analogous CycloMedia. These web services give an extremely realistic perception of reality and are practical-through the overlapping of images-in supporting before-and-after event analyses (for example, Japan before and after the 2011 tsunami).

\subsection{Augmented Reality}

Augmented reality is presently the most powerful tool for the integration of digital data with the real-world

\footnotetext{
3 www.floodlist.com.

4 www.ushahidi.com.

5 www.floodbook.it.

${ }^{6}$ https://www.historypin.org/en.

${ }^{7}$ http://www.whatwasthere.com.
}

environment-in particular if used on a mobile deviceand represents "perceptive lenses," capable of adding digital information, generally visual or auditive, to the reality perceived by the senses. The most widespread applications are in the field of advertising, or in the tourism sector, where applications have specifically been developed to integrate vintage images to the current environment. This allows for a "double vision" of the surrounding space, creating a very captivating effect (Azavea and City of Philadelphia Department of Records 2011). Already available application programming interfaces in current smartphone operating systems suggest an interesting transposition of the same technologies for social communication with respect to risk and warnings for civil defense purposes, particularly as directed toward the younger generations.

\section{Case Studies}

Some of the communication strategies and tools proposed in the previous sections are applied in this study to three well-documented past flood events in Italy. The combination of climatic, meteorological, geological, and morphological conditions in Italy is particularly favorable to the occurrence of harmful events. In the south of the peninsula, when high-intensity, short-duration convective storms strike, highly destructive flash floods occur, and sometimes large clusters of destructive shallow landslides are triggered. In the northern part of the country, high-intensity and prolonged rainfall events, combined with the availability of debris on steep slopes, promote the occurrence of debris flows in mountain environments (Salvati et al. 2010). Three case studies are presented: (1) Salerno and Amalfi coast, 25-26 October 1954; (2) Genoa, 4 November 2011; and (3) Sardegna, 18 November 2013.

The 1954 meteorological event is considered the most catastrophic one to ever occur along the Amalfi Peninsula, located between Naples and Salerno. The rainfall lasted for 16 hours with a total value of $504 \mathrm{~mm}$ and maximum intensity of $150 \mathrm{~mm} / \mathrm{h}$ (Frosini 1955). A disaster of mega proportions affected 46 villages, caused the collapse of numerous houses, and the almost complete interruption of telegraph and telephone communications. Floods and heavy erosion, as well as mudflows, debris flows, and rockfalls occurred over a wide area of about $90 \mathrm{~km}^{2}$, including Salerno, Vietri sul Mare, Cava dei Tirreni, Maiori, Minori, and Tramonti (Esposito et al. 2003), producing destructive flood and mud waves. There were 318 casualties and 350 people were injured (Violante et al. 2009).

The 2011 flood event in Genoa occurred in the autumn and affected a small part of a very densely urbanized 
coastal area of the country. The high atmospheric instability, which lasted for 10 days, was of particularly high magnitude and intensity and gave rise to some Italian alltime records in rainfall. In particular, on 4 November the peak of maximum rainfall was measured at 11.30 a.m. at the Vicomorasso rainfall station and resulted in $181 \mathrm{~mm}$ rainfall in $1 \mathrm{~h}$, while $500 \mathrm{~mm}$ of rain were recorded in six hours (Parodi et al. 2012). Although the city of Genoa is historically placed in an area with high flash-flood hazard, incomplete alert management, very quick development of the flooding, and poor training in self-protection behavior were the causes that led to six casualties.

The 2013 cyclone in Sardegna brought extremely heavy rain over an extensive area, compared to the other two events, of up to $1500 \mathrm{~km}^{2}$, with several stations recording close to $450 \mathrm{~mm}$ of rain in $12 \mathrm{~h}$ (from 07:00 a.m. to 7:00 p.m. on 18 November), a maximum daily rainfall of $469.6 \mathrm{~mm} /$ day and a maximum intensity rate of $109.4 \mathrm{~mm} /$ $\mathrm{h}$, resulting in widespread and severe flooding (Amponsah et al. 2014). In the following, examples of the application of visual tools to these events are outlined.

\subsection{Amalfi Coast, 25-26 October 1954}

To reconstruct this historic event, the following tools were used:

- Google Earth maps with geo-referenced photos, videos, and aerial images;

- Virtual 3D reconstructions through SketchUp;

- Historical videos from the "Istituto Luce," based in Rome, which holds the largest collection of cinematographic material for educational and informative purposes in Italy;

- Comparison of historical pictures with the present through street view services;

- Material from newspapers and magazines of the time found in local libraries.

Figure 1 shows an example of the work done to compare old images of the city of Vietri sul Mare just after the flood event with current street view images.

Figure 2 shows the virtual reconstruction of a building that collapsed during the 1954 flood. By using historical photos from before the flood event and photos of the same building after the flood event it was possible to reconstruct the parts of the structure that collapsed as a consequence of the water flow. The freeware software (SketchUp) was used.

In Fig. 3, the landscape setting and the urban canvas of the city of Vietri sul Mare in 1954 were recreated. The urban area closer to the sea that occupies about 7 ha today was located on the small outlet fan of a creek. Historical aerial photos helped to recreate the 1954 degree of urbanization (Fig. 3a) and flood damage. The Google Earth image in Fig. $3 \mathrm{~b}$ shows the structures destroyed by the water during the flood that were later rebuilt (in red) and those that did not undergo reconstruction (in purple).

This type of representation and information helps to provide citizens with a simplified - though rigorous-experience of the effects of the interactions between stream flows and buildings, as an essential prerequisite for creating sensibility to sources of flooding risks in the city.

\subsection{Genoa, 4 November 2011}

The tools and strategies that were used for this flood event include Google Earth maps with geo-referenced videos and self-protection advice, the collection and geo-tagging of amateur videos, and the development of both a thematic blog and a crowdmap. The videos used to reconstruct this flood event are mainly amateur videos. Silvestro et al. (2012) used an amateur video made by a citizen during the flooding and available in near real-time on YouTube to estimate the peak flow of the Fereggiano creek. Thanks to Google tools each video is geographically located and can be visualized within the map framework of Google Earth.

Two web platforms, in the form of a crowdmap ${ }^{8}$ and a thematic $\operatorname{blog}^{9}$, were developed after the event. Figure 4 shows the interface to which the users sent their personal accounts or videos of the event. The videos show that people were not prepared for the flood-for example, protective measures were not placed near schools and commercial premises to mitigate a likely flood event, and numerous people crossed the impetuous water flow by car or on foot without taking the appropriate measures.

\subsection{Sardegna, 18 November 2013}

The tools and strategies that were used for the representation of the Sardegna flood are Google Earth maps with geo-referenced videos and rainfall data, and the collection and geo-tagging of amateur videos.

The first operation was performed on the Google Earth map. The damages caused by the event were identified with a symbol and geographical coordinates (Fig. 5). The meteorological event analysis was completed through the identification of rain gauges within the interactive map, accompanied by the insertion of daily cumulative values for each station. In the second operation, each placeholder of documented damage was connected to one or more photographs (through their URL address) and, if available, one or more movies (through the "Embed" function, as in the case of videos on YouTube, or their web address). This

\footnotetext{
${ }^{8}$ https://genovaflood.crowdmap.com.

9 https://genovaflood.wordpress.com.
} 


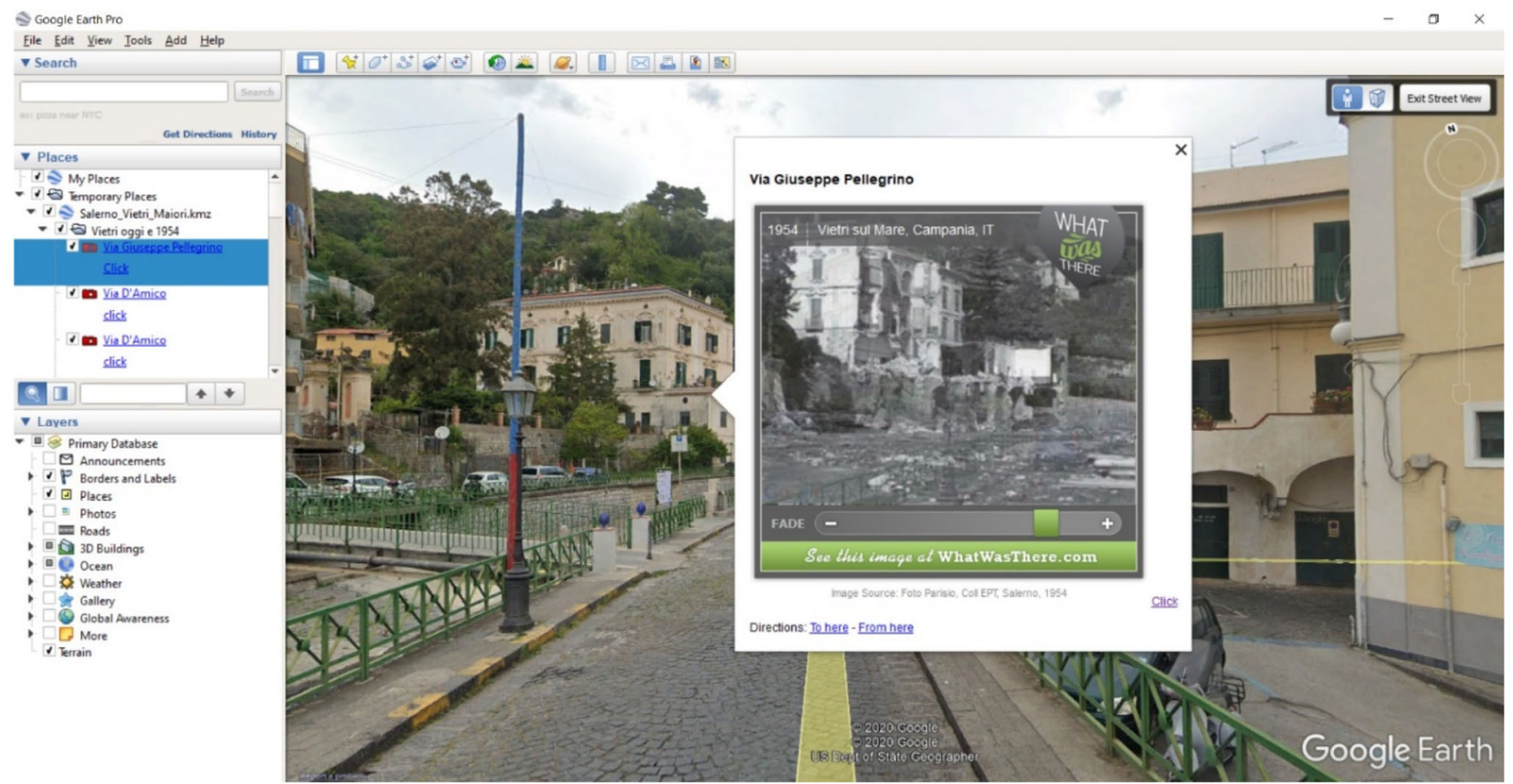

Fig. 1 Example of a KMZ file that contains geolocalized images taken during the 25-26 October 1954 Vietri sul Mare flash flood in Italy. Taking advantage of both Google Street View and
WhatWasThere it is possible to perform a quick visual inspection of the damages and the recovery phase
Fig. 2 Analysis of the Palazzo Pellegrino in Vietri sul Mare that partially collapsed during the 1954 flash flood. a 3D model of the building; b Photo taken after the flash flood; c 3D reconstruction of the collapsed part of the building; $\mathbf{d}$ Overlap between the post-event photo and the $3 \mathrm{D}$ reconstruction (a)
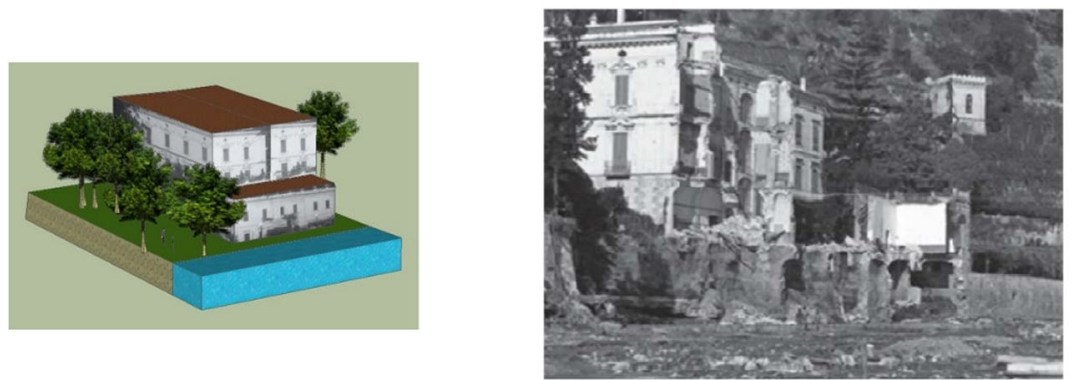

(b)

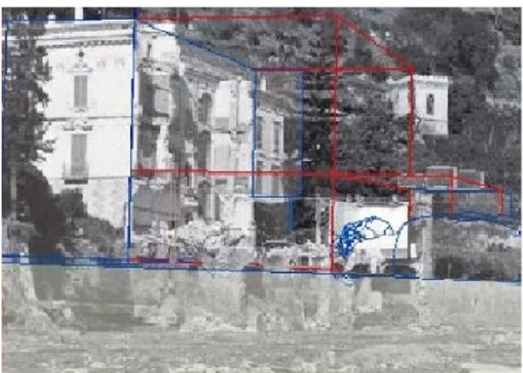

function allows people to recognize the geographical context of damage through interactive navigation.

The KMZ files that can easily be opened by open-source software or apps, and the extensive use of web material, accessible through links connected to the placeholders, offers documentation supports that are easy to transfer and to navigate in. For use in schools and in demonstration or also for widespread dissemination, these documents allow a useful interactive approach to the reproduction of the event development. 

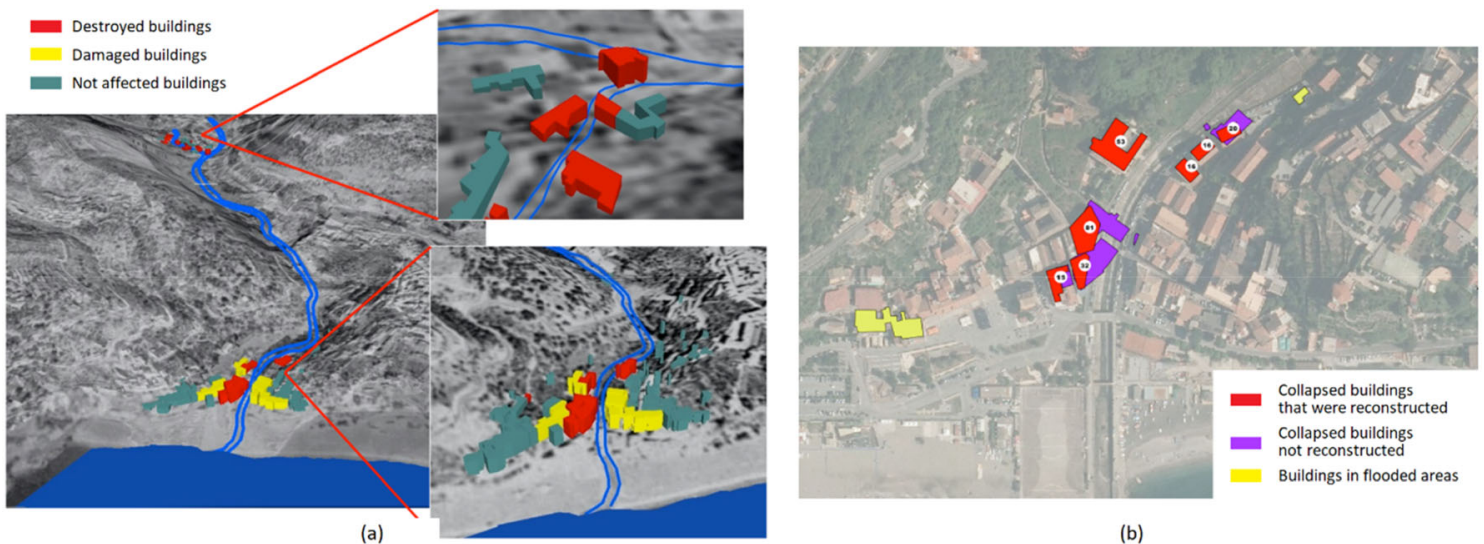

(b)

Fig. 3 Aerial photo maps of Vietri sul Mare. a Significant buildings in the immediate post-event of 1954: destroyed (red), damaged (yellow), not affected (green); b Post-reconstruction map with the identification of the collapsed buildings that were reconstructed

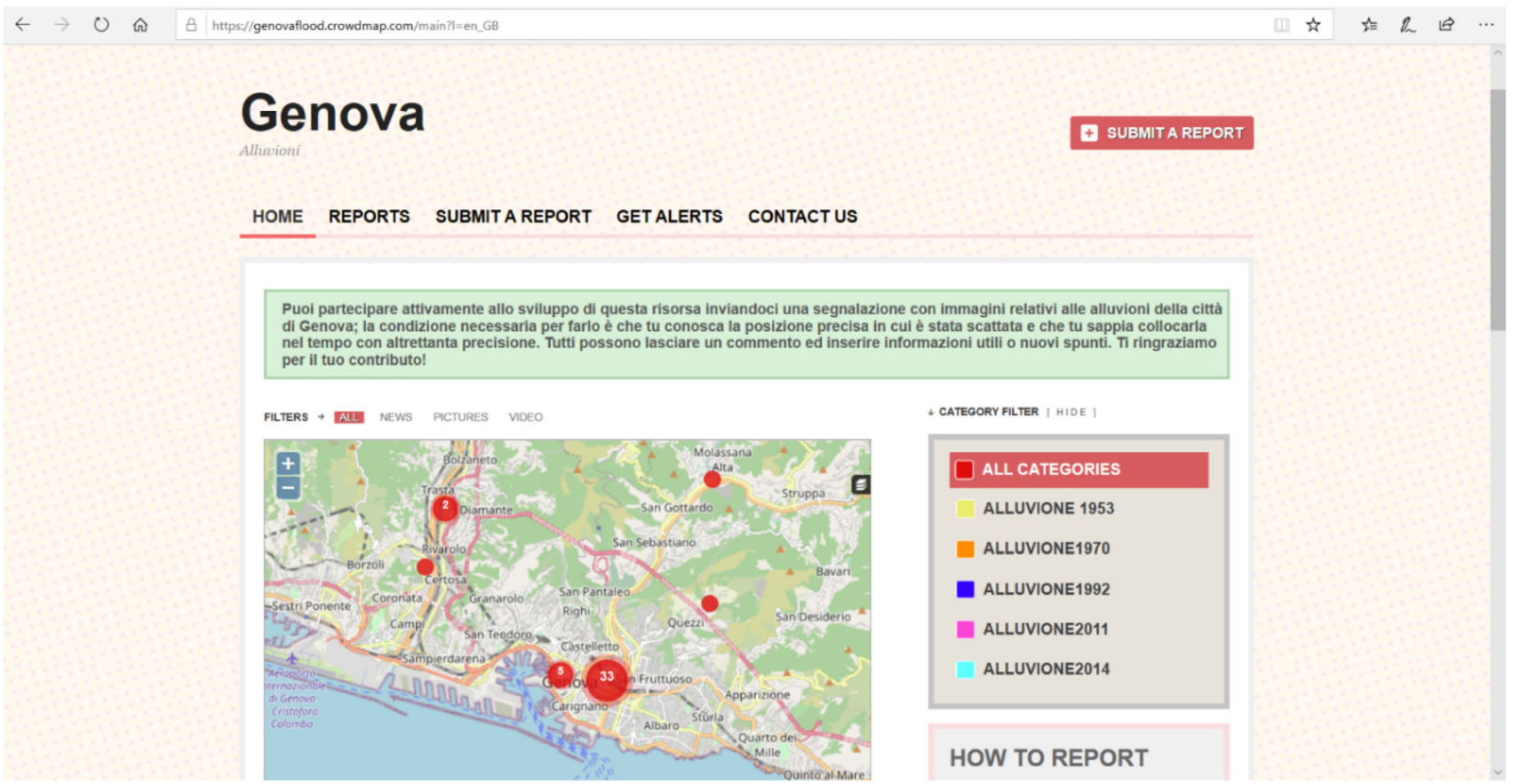

Fig. 4 Crowdmap produced for collecting information on the 2011 Genoa flood event. Source https://genovaflood.crowdmap.com.

\section{Conclusion}

The construction of the multimedia tools described in this article was undertaken to demonstrate how the typical content of DRs issued in Italy can undergo potential improvements for broader social communication, particularly if associated with a narrative structure, as the case studies suggest, to increase people's awareness of flood risks.

Disaster reports provide much information that contributes to these objectives, but they are mainly expressed in a technical language and addressed to a technical readership. To pursue new social communication approaches, the already available information in DRs could be integrated with significant visual elements and with a storyline to create a disaster tale. New elements should preferably include videos and pictures with a personal point of view, personal accounts, and memories.

Suitable visual tools offered online, and relevant for the casualties, the damages, the area, and the urban settlements affected, were taken into consideration and used in three case studies in Italy. Some information media-historical stories from newspapers or books, presence of historically interesting photos or videos, reliability of the source of information, broadcasting coverage, and involvement of experts in risk management-can contribute to the 


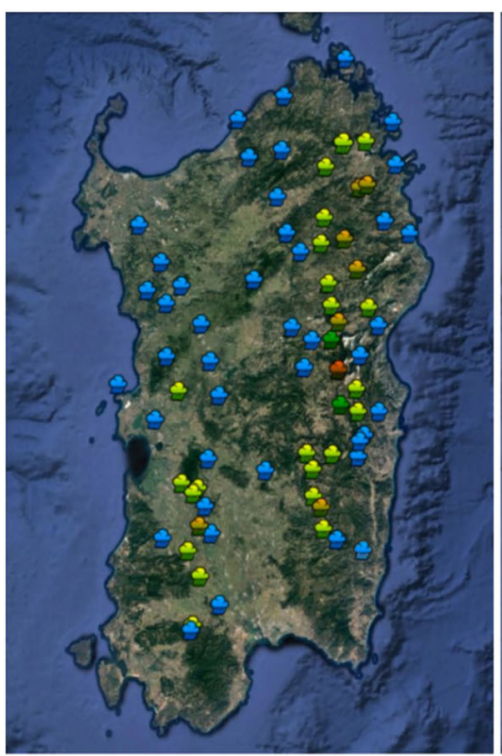

Accumulated rainfall:

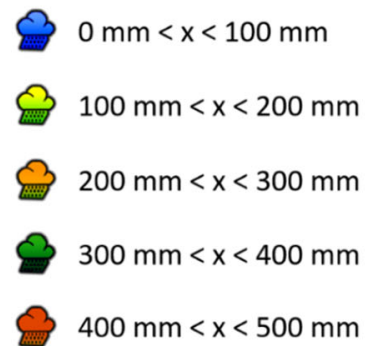

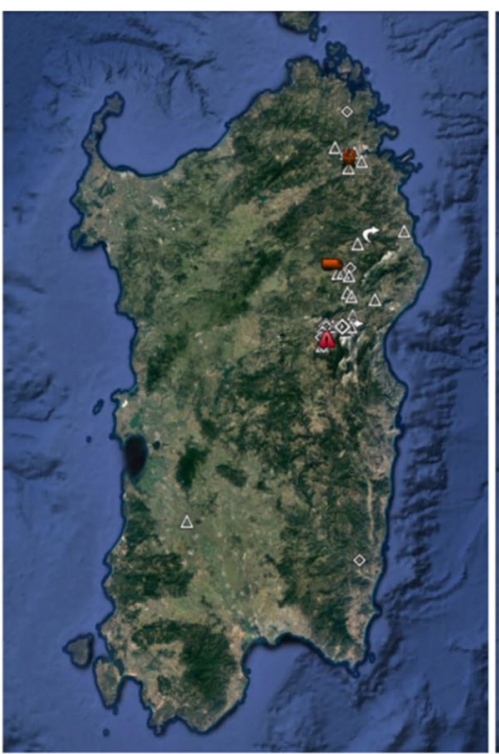

Damages to the road network:

$\triangle$ High entity damage

Minor entity damage

Videos:

Q Amateur video

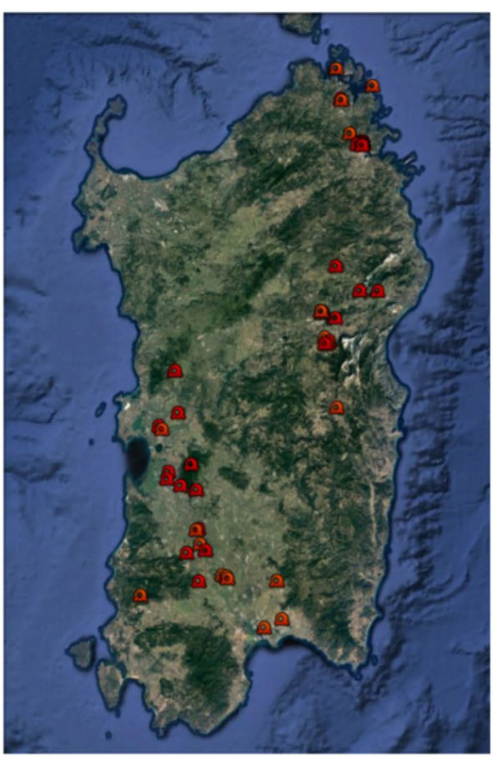

Other:

Damaged building sites

Train derailment

Firefighters accident

Dam overflow

Fig. 5 Map with geotagged videos, photos, and rain gauges created for the 2013 Sardegna flood event using Google Earth

development of the concept of "danger" in every single citizen. The viewing of photos or videos, regarding for example the destruction of buildings, can convey intense negative emotions to people, which can encourage them to look for the best solutions to mitigate this type of risk. However, it is important to highlight that DTs should be drawn up using reliable standards, and the file formats should be maintained over time to be accessible in the long term.

The historical analysis of the 1954 Salerno and Amalfi coast case study shows that the indirect experience, through information taken from the mass media, helps people remember and reconstruct a flood event, thus motivating them to undertake actions of self-protection against a new probable flood and pass their knowledge on to their children (for example, by telling the story of the event and passing it on to grandchildren, relatives, and so on). Unlike their grandparents, children/adolescents living in Vietri sul Mare have never experienced a flood, so they perceive the flood risk in a different and more superficial way compared to the perception their grandparents had.
People in Genoa in 2011 had insufficient training in the precautionary measures that need to be implemented in case of repeated weather alerts (had the population received training on the actions to be taken? If so, why didn't they behave properly? Did emotions and fears influence their decisions?). It is also clear that the information provided as a warning was not clear for the affected population. To capture people's engagement in the training, a fundamental benefit of using web tools is the ability for people to collaborate, collect and share information, and work together online (Ashley et al. 2009). Blogs allow one to reach as many people as possible and involve them in the preparation of material for online discussion. Exactly how online crowdsourcing platforms are increasingly used by global companies to connect with and get feedback from users (Hossain 2012), this mechanism can reinforce social knowledge about flood resilience.

The early results of this study suggest that such an upgraded communication strategy can be used in support of initiatives that encourage the informed participation of citizens in the public consultations required by the Directive 2007/60/EC. Even though the member states of the 
United Nations have stressed the necessity of increasing engagement (UNISDR 2015), community exclusion remains a widely known issue-only $16 \%$ of people at risk feel that they are included in decisions about how to reduce their own risk and in taking actions to reduce threats; therefore, actions taken to address a problem may be less effective (GNDR 2019). Disaster tales play two fundamental roles: first, they make relevant information understandable for non-specialized users and, second, they can help to increase community engagement.

In terms of future developments, what we propose here can be strongly enhanced by the use of augmented reality environments that can allow ubiquitous, collaborative, and situated learning through computer simulations, games, models, and virtual objects in real environments (Broll et al. 2008). Augmented reality has the potential to bridge the gap between learning in formal and informal settings, increase people's motivation and interest, and help learners develop skills and knowledge learned in a more effective way (Wu et al. 2013). The development of a methodology for scientists and civil protection staff to follow during the writing of the disaster tales is highly recommended.

Acknowledgements The authors acknowledge Politecnico di Torino, Italy, for providing the funding that contributed to the research results reported in this article.

Open Access This article is licensed under a Creative Commons Attribution 4.0 International License, which permits use, sharing, adaptation, distribution and reproduction in any medium or format, as long as you give appropriate credit to the original author(s) and the source, provide a link to the Creative Commons licence, and indicate if changes were made. The images or other third party material in this article are included in the article's Creative Commons licence, unless indicated otherwise in a credit line to the material. If material is not included in the article's Creative Commons licence and your intended use is not permitted by statutory regulation or exceeds the permitted use, you will need to obtain permission directly from the copyright holder. To view a copy of this licence, visit http://creativecommons. org/licenses/by/4.0/.

\section{Reference}

Amponsah, W., M. Borga, L. Marchi, E.I. Nikolopoulos, F. Marra, S. Crema, M. Pirastru, D. Zoccatelli, et al. 2014. The flash-flood of November 2013 in NE Sardinia (Italy): Post-event documentation and hydrological modeling. In Proceedings of the 8th International HyMeX Workshop, 15-18 September 2014, La Valletta, Malta.

Ashley, H., J. Corbett, D. Jones, B. Garside, and G. Rambaldi. 2009. Change at hand: Web 2.0 for development. Nottingham: International Institute for Environment and Development (IIED). https://pubs.iied.org/pdfs/14563IIED.pdf. Accessed 14 Oct 2020.

Azavea and City of Philadelphia Department of Records. 2011. Implementing mobile augmented reality technology for viewing historic images. Philadelphia, PA: Azavea and City of Philadelphia Department of Records. https://www.azavea.com/wp-
content/uploads/2016/05/Augmented_Reality_by_PhillyHis tory_Whitepaper_v02.pdf . Accessed 14 Oct 2020.

Botzen, W.J.W., J.C.J.H. Aerts, and J.C.J.M van den Bergh. 2009. Dependence of flood risk perceptions on socioeconomic and objective risk factors. Water Resources Research 45(10): Article W10440.

Brilly, M., and M. Polic. 2005. Public perception of flood risks, flood forecasting and mitigation. Natural Hazards and Earth System Sciences 5(3): 345-355.

Broll, W., I. Lindt, I. Herbst, J. Ohlenburg, A.K. Braun, and R. Wetzel. 2008. Toward next-gen mobile AR games. IEEE Computer Graphics and Applications 28(4): 40-48.

Cagnati, A., and I. Chiambretti. 2009. Avalanche risk. Human factor and heuristic traps. (Rischio valanghe. Fattore umano e trappole euristiche). In Neve e Valanghe, 66. Trento: AINEVA. https:// issuu.com/aineva7/docs/nv66. Accessed 14 Oct 2020 (in Italian).

de Bruijn, K.M., N. Lips, B. Gersonius, and H. Middelkoop. 2016. The storyline approach: A new way to analyse and improve flood event management. Natural Hazards 81(1): 99-121.

Denning, S. 2005. The leader's guide to storytelling: Mastering the art and discipline of business narrative. San Francisco, CA: Jossey-Bass.

Esposito, E., S. Porfido, C. Violante, and F. Alaia. 2003. Disaster induced by historical floods in a selected coastal area (Southern Italy). In Palaeofloods, historical floods and climatic variability: Applications in flood risk assessment. Proceedings of the PHEFRA Workshop, 16-19 October, 2002, Barcelona, ed. V.R. Thorndycraft, G. Benito, M. Barriendos, and M.C. Llasat, 143-148. Madrid: CSIC - Centro de Cientas Medioambientales.

Fisher, W.R. 1984. Narration as a human communication paradigm: The case of public moral argument. Communication Monographs 51(1): 1-22.

Frosini, P. 1955. The 25-26 October 1954 Salerno storm (Il nubrifagio di Salerno del 25-26 Ottobre 1954). In Giornale Genio Civile 3-4: 179-188. Roma: Istituto Poligrafico dello Stato (in Italian).

GNDR (Global Network of Civil Society Organisations for Disaster Reduction). 2019. View from the Frontline Global Report 2019. https://global-report.vfl.world. Accessed 14 Oct 2020.

Hinyard, L.J., and M.W. Kreuter. 2007. Using narrative communication as a tool for health behavior change: A conceptual, theoretical, and empirical overview. Health Education \& Behavior 34(5): 777-792.

Hossain, M. 2012. Users' motivation to participate in online crowdsourcing platforms. In Proceedings of the 2012 International Conference on Innovation Management and Technology Research, 21-22 May 2012, Malacca, Malaysia, 310-315.

Hutton, D. 2008. Older people in emergencies: Considerations for action and policy development. Geneva: World Health Organization. http://www.who.int/ageing/publications/Hutton_report_ small.pdf. Accessed 14 Oct 2020.

Janzik, L. 2010. Contribution and participation in innovation communities: A classification of incentives and motives. International Journal of Innovation and Technology Management 7(3): 247-262.

Jones, S., C. Kirchsteiger, and W. Bjerke. 1999. The importance of near miss reporting to further improve safety performance. Journal of Loss Prevention in the Process Industries 12(1): $59-67$.

Jonkman, S.N., and I. Kelman. 2005. An analysis of the causes and circumstances of flood disaster deaths. Disasters 29(1): 75-97.

Kellens, W., T. Terpstra, and P. De Maeyer. 2013. Perception and communication of flood risks: A systematic review of empirical research. Risk Analysis 33(1): 24-49.

Kreuter, M.W., M.C. Green, J.N. Cappella, M.D. Slater, M.E. Wise, D. Storey, E.M. Clark, D.J. O'Keefe, et al. 2007. Narrative 
communication in cancer prevention and control: a framework to guide research and application. Annals of Behavioral Medicine 33(3): 221-235.

Lara, A., D. Saurí, A. Ribas, and D. Pavón. 2010. Social perceptions of floods and flood management in a Mediterranean area (Costa Brava, Spain). Natural Hazards and Earth System Sciences 10(10): 2081-2091.

Lee, H., J. Fawcett, and R. DeMarco. 2016. Storytelling/narrative theory to address health communication with minority populations. Applied Nursing Research 30: 58-60.

Lindell, M.K., and R.W. Perry. 2012. The protective action decision model: Theoretical modifications and additional evidence. Risk Analysis 32(4): 616-632.

Miceli, R., I. Sotgiu, and M. Settanni. 2008. Disaster preparedness and perception of flood risk: A study in an alpine valley in Italy. Journal of Environmental Psychology 28(2): 164-173.

Murphy, S.T., L.B. Frank, J.S. Chatterjee, and L. BaezcondeGarbanati. 2013. Narrative versus nonnarrative: The role of identification, transportation, and emotion in reducing health disparities. Journal of Communication 63(1): 116-137.

Parodi, A., G. Boni, L. Ferraris, F. Siccardi, P. Pagliara, E. Trovatore, E. Foufoula-Georgiou, and D. Kranzlmueller. 2012. The "perfect storm": From across the Atlantic to the hills of Genoa. Eos, Transactions American Geophysical Union 93(24): 225-226.

Ruin, I., J.D. Creutin, S. Anquetin, and C. Lutoff. 2008. Human exposure to flash floods-Relation between flood parameters and human vulnerability during a storm of September 2002 in Southern France. Journal of Hydrology 61(1-2): 199-213.

Salvati, P., C. Bianchi, M. Rossi, and F. Guzzetti. 2010. Societal landslide and flood risk in Italy. Natural Hazards and Earth System Sciences 10(3): 465-483.
Salvati, P., C. Bianchi, F. Fiorucci, P. Giostrella, I. Marchesini, and F. Guzzetti. 2014. Perception of flood and landslide risk in Italy: A preliminary analysis. Natural Hazards and Earth System Sciences 14(9): 2589-2603.

Sanne, J.M. 2008. Incident reporting or storytelling? Competing schemes in a safety-critical and hazardous work setting. Safety Science 46(8): 1205-1222.

Silvestro, F., S. Gabellani, F. Giannoni, A. Parodi, N. Rebora, R. Rudari, and F. Siccardi. 2012. A hydrological analysis of the 4 November 2011 event in Genoa. Natural Hazards and Earth System Sciences 12(9): 2743-2752.

Tang, Z., L. Zhang, F. Xu, and H. Vo. 2015. Examining the role of social media in California's drought risk management in 2014. Natural Hazards 79(1): 171-193.

UNISDR (United Nations International Strategy for Disaster Reduction). 2015. Sendai framework for disaster risk reduction 2015-2030. https://www.preventionweb.net/files/43291_sendai frameworkfordrren.pdf. Accessed 14 Oct 2020.

Violante, C., C. Biscarini, E. Esposito, F. Molisso, S. Porfido, and M. Sacchi. 2009. The consequences of hydrological events on steep coastal watersheds: The Costa d'Amalfi, eastern Tyrrhenian Sea. In The role of hydrology in water resources management, ed. H.J. Liebscher, R. Clarke, J. Rodda, G. Schultz, A. Schumann, L. Ubertini, and G. Young, 102-113. Wallingford, UK: IAHS Press.

Wu, H.K., S.W.Y. Lee, H.Y. Chang, and J.C. Liang. 2013. Current status, opportunities and challenges of augmented reality in education. Computers \& Education 62: 41-49.

Xia, J., R.A. Falconer, B. Lin, and G. Tan. 2011. Numerical assessment of flood hazard risk to people and vehicles in flash floods. Environmental Modelling \& Software 26(8): 987-998. 